\title{
T4 non-small cell lung cancer invading the heart or the major thoracic vessels
}

\author{
Elisa De Franceschi, Andrea Dell'Amore, Alice Bellini, Alessandro Pangoni, Michele Dario Russo, \\ Matilde Rocchi, Giovanni Maria Comacchio, Giorgio Cannone, Marco Mammana, Marco Schiavon, \\ Andrea Zuin, Federico Rea
}

Department of Cardiac, Thoracic, Vascular Sciences and Public Health, Thoracic Surgery Unit, University of Padova, Padova, Italy

Contributions: (I) Conception and design: E De Franceschi, A Dell'Amore, F Rea; (II) Administrative support: A Zuin, M Schiavon, M Mammana;

(III) Provision of study materials or patients: A Bellini, G Cannone; (IV) Collection and assembly of data: MD Russo, M Rocchi, GM Comacchio; (V)

Data analysis and interpretation: E De Franceschi, A Bellini, A Pangoni; (VI) Manuscript writing: All authors; (VII) Final approval of manuscript: All authors.

Correspondence to: Andrea Dell'Amore, MD. Thoracic Surgery Unit, Department of Cardiac, Thoracic and Vascular Sciences, University of Padova, Via Giustiniani 2, 35128, Padova, Italy. Email: dellamore76@libero.it.

Background: Stage T4 non-small cell lung cancer (NSCLC) includes a heterogeneous group of locally advanced tumours. The role of surgery in these cases is still under debate. The aims of this retrospective study are to analyse oncological and surgical outcomes and to examine prognostic factors affecting survival of T4-NCSLC invading great vessels or heart.

Methods: Data of 108 T4-NSCLC surgically treated patients at our Institution from 1990 to 2019, were retrospectively collected, focusing on demographics, comorbidities, surgical approach, extension of pulmonary resection, type of cardio-vascular resection, use of cardiopulmonary bypass (CPB) or extracorporeal membrane oxygenation (ECMO), neoadjuvant or/and adjuvant therapy and peri/postoperative complications. The population was classified in 5 groups based on the involved organ: pulmonary artery $(\mathrm{PA})(\mathrm{n}=32)$, left atrium $(\mathrm{LA})(\mathrm{n}=24)$, superior vena cava $(\mathrm{SVC})(\mathrm{n}=23)$, aorta $(\mathrm{n}=21)$, and subclavian $\operatorname{artery}(\mathrm{n}=8)$.

Results: There were 86 males $(80 \%)$ and 22 females (20\%) with a median age at surgery of 67 years (range, 60-73 years). Squamous cell carcinoma histology was the most represented (71\%). Mediastinal lymph nodes were pathologically involved in $67 \%$ of the cases. Intrapericardial cardio-vascular invasion was detected in $39 \%$ of the patients. Pneumonectomy was performed in $52 \%$ of cases. Vascular reconstruction and angioplasty or sub-adventitial dissection were necessary in $29 \%$ and $58 \%$ of the patients, respectively. Complete surgical resection was achieved in $82 \%$. Induction and adjuvant therapies were administrated in $41 \%$ and $60 \%$ of patients, respectively. Fifty-two patients (48\%) developed perioperative complications, while $25(23 \%)$ late complications. Thirty-day mortality rate was $2 \%$. After a median follow up of 17 months (range, 9-48 months), 66 patients (61\%) experienced recurrence, with a median disease-free survival (DFS) of 7.5 months. The pattern of relapse was local in 21 patients (19\%), distant in 33 patients (30\%) and local + distant in 13 patients (12\%). The overall 1-, 3- and 5-year survival rates were $75 \%, 34 \%$ and $27 \%$, respectively. Predictors of better OS were the use of induction chemotherapy and non-squamous histology.

Conclusions: In our experience surgical treatment of T4-NSCLC with vessels or heart infiltration gain acceptable risk in term of mortality and morbidity. A multidisciplinary evaluation and approach are mandatory to improve survival and to reduce recurrence of the disease; in particular, induction chemotherapy seems to have a positive effect.

Keywords: Non-small cell lung cancer (NSCLC); locally advanced lung cancer; vascular reconstruction; aorta; superior vena cava resection 
Received: 25 March 2020; Accepted: 14 May 2020; Published: 25 August 2020.

doi: $10.21037 /$ ccts-20-63

View this article at: http://dx.doi.org/10.21037/ccts-20-63

\section{Introduction}

Lung cancer is the main cause of cancer-related death worldwide. According to the VIII edition of tumor node metastasis (TNM), T4 non-small cell lung cancer (NSCLC) is a heterogenous group $(1,2)$. In this framework, the role of surgery for locally advanced lung carcinomas has been debated; in particular, thoracic malignancies invading vital organs, such as the heart or great vessels, were often considered unresectable and treated with palliative chemo and/or radiotherapy (3). Recent advances in surgical procedures, chemo-radiotherapy and perioperative care have increased the number of carefully selectable patients eligible for aggressive multimodality therapy, including highly invasive surgical treatments (4). According to the literature, the main predictors of outcomes are the nodal status and the completeness of resection (5). In this scenario, the role of induction therapy is uncertain: it helps in increasing the likelihood of complete resection, downstaging nodal disease and, in some cases, allowing surgical treatment for malignancies previously unresectable, but it has been associated with an increased risk of surgical complications and respiratory failure $(5,6)$. The aims of this retrospective study are to analyze oncological and surgical outcomes and to examine prognostic factors affecting survival of T4-NCSLC invading great vessels or heart.

\section{Methods}

From June 1990 to September 2019, 108 patients with T4-NSCLC invading the great vessels or the heart underwent surgery at Padua University Hospital. Data on clinical, surgical and pathological characteristics were retrospectively collected. Clinical data were analyzed including demographics (age and gender), comorbidities (such as diabetes, chronic obstructive pulmonary disease (COPD) and cardio-vascular diseases), smoking history, organ invasion, histologic type, induction and adjuvant therapy, time of hospital stay and need of intensive care unit (ICU) stay.

Among surgical data, we collected elements about surgical approach, extension of pulmonary resection, type of cardio-vascular resection and the use of cardiopulmonary bypass $(\mathrm{CPB})$ or extracorporeal membrane oxygenation (ECMO). Study approval by local ethic commitment was achieved (No. CH-T00.4598PD19). Informed consent was taken from all individual participants. The study was conducted in accordance with the Declaration of Helsinki (as revised in 2013).

Patients were staged according to $8^{\text {th }}$ TNM classification system. According to organ invasion, patients were subdivided in five groups based on infiltration of one or more cardio-vascular structures (Figure 1). Followup information was obtained from clinical visit, imaging studies and phone interview. We analyzed perioperative outcomes, overall survival, disease free survival, pattern of relapse and its treatment. All the relevant clinical, surgical and pathological variables were studied to identify possible prognostic factors affecting survival.

\section{Statistical analysis}

The data were reported as absolute numbers, percentage or median values with interquartile range (IQR). The comparison between qualitative variables was verified with $\chi^{2}$-test or Fischer's test when opportune. The Coxregression was used to calculate unadjusted hazard ratio (HR) for prognostic factors of long-term survival and disease-recurrence. The Kaplan-Meier method was used for survival and disease-free analysis. Survival curves were compared with long-rang test. $\mathrm{P}<0.05$ was considered statistically significant. All the statistical analyses were performed using SPSS 20.0 version for windows (SPSS, Inc., Chicago, IL, USA).

\section{Results}

The median age of the patients was 67 years (IQR, 6073 years), 86 were males $(80 \%)$ and 22 were females (20\%); 81 patients $(75 \%)$ were smokers or former smokers. Seventy-six patients $(70 \%)$ presented with comorbidities; in particular, 10 patients (9\%) were affected by COPD, $10(9 \%)$ had diabetes and $38(35 \%)$ had cardiovascular diseases. Some patients had two or more comorbidities, and data were not available for 2 patients. We noted a median hospital stay of 14 days (IQR, 11-17 days). Fifty- 

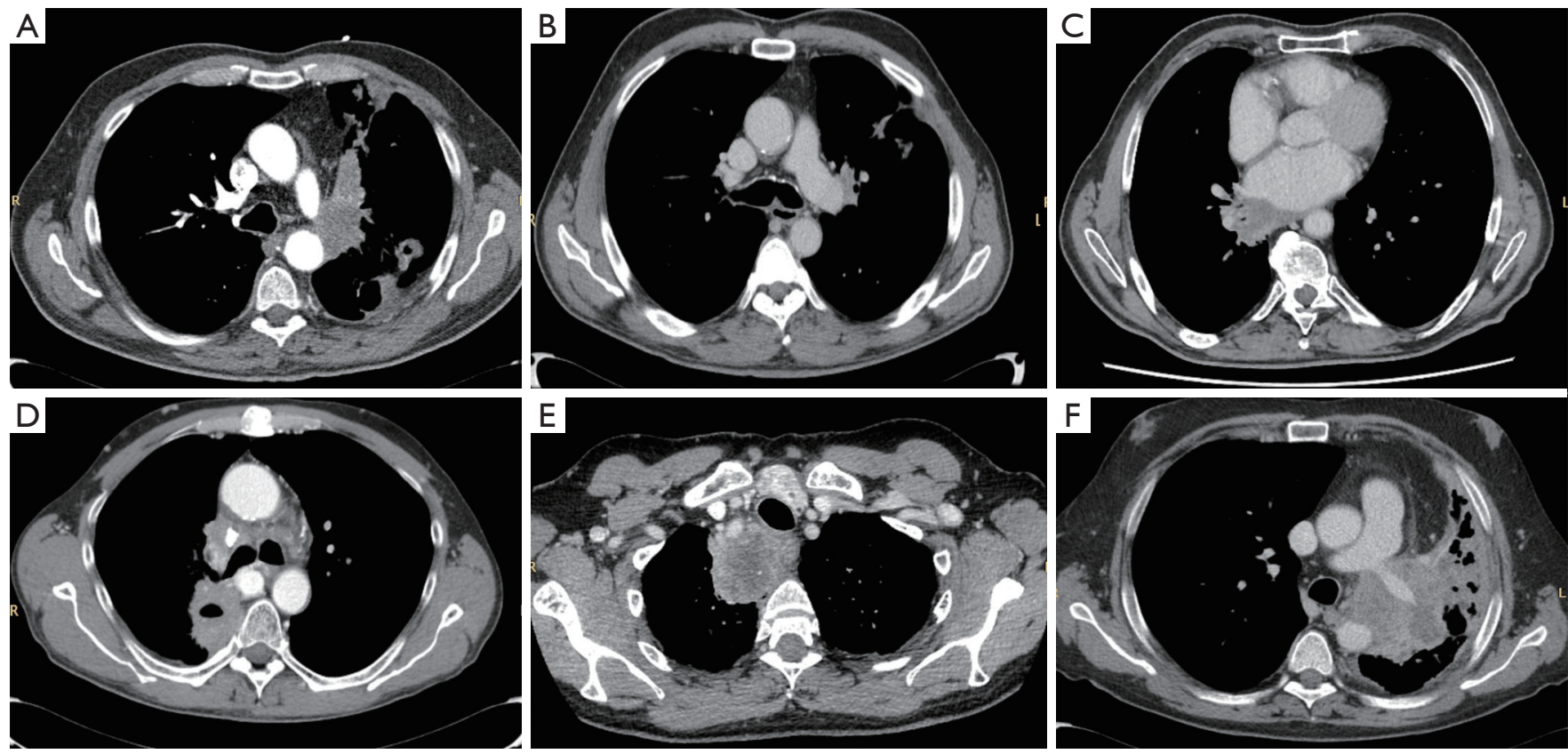

Figure 1 Examples of CT scan showing different vascular invasion. (A) Descending thoracic aorta infiltration; (B) main left pulmonary artery infiltration; (C) left atrium wall infiltration; (D) superior vena cava infiltration with lumen thrombosis; (E) right Pancoast tumor with subclavian artery infiltration; (F) a case of double infiltration of the main pulmonary artery and of the descending thoracic aorta.

nine patients $(55 \%)$ needed ICU stay with a median time of 1 day (IQR, 0-2 days). Clinical data are reported in Table 1.

Forty-four patients $(41 \%)$ received neoadjuvant therapy: 26 patients $(24 \%)$ chemotherapy, 2 (2\%) radiotherapy and $16(15 \%)$ chemo-radiotherapy.

Pathological examination showed 77 patients (71\%) with squamous cell carcinoma, 26 (24\%) with adenocarcinoma and $5(5 \%)$ with other histology; 72 patients $(67 \%)$ presented with metastasis in loco-regional nodes. Oncological complete resection (R0) was achieved in 88 patients (82\%), 18 patients had an R1 resection. Two patients with extensive infiltration of the aortic arch and the main pulmonary artery (PA) respectively had a R2 resection. Involved organs were divided in five categories: infiltration of the aorta in $21(20 \%)$ cases, invasion of the left atrium (LA) in $24(22 \%)$ cases, infiltration of the superior vena cava (SVC) in $23(21 \%)$ cases and invasion of the $\mathrm{PA}$ in $32(30 \%)$ cases. The remaining 8 patients $(7 \%)$ were classified as Pancoast's tumors with invasion of the subclavian artery. Intrapericardial cardio-vascular invasion was found in 42 cases (39\%). Tumor was right-sided in 44 patients (41\%) and left-sided in 64 (59\%). Surgical access was a posterolateral thoracotomy in 100 patients (92\%), sternotomy in $1(1 \%)$, sternothoracotomy in $5(5 \%)$ and clamshell incision in 2 (2\%). CPB or ECMO was necessary in 5 patients. The most frequent pulmonary resection was pneumonectomy (52\%), followed by lobectomy (29\%). Twelve patients (11\%) underwent sleeve resections: 11 sleeve lobectomies (5 bronchovascular sleeves) and 1 tracheal sleeve lobectomy. Moreover, bilobectomy and sublobar resection were realized in $6(5 \%)$ and $3(3 \%)$ cases, respectively. Surgeons performed vascular reconstruction in 31 patients (29\%) and LA resection in 27 cases (25\%). Vascular reconstruction after tangential resection was achieved with direct prolene suture in 10 patients and with heterologous pericardium patch in 11 patients. A complete vascular substitution with a polytetrafluoroethylene conduit was performed in 10 patients. Sixty-three patients (58\%) underwent angioplasty or sub-adventitial dissection. In some surgical procedures more than one techniques were needed. Adjuvant therapy was performed in 65 cases (60\%). Surgical and pathological factors are presented in Table 2.

\section{Perioperative and postoperative complications}

Four patients (4\%) had intraoperative complication: bleeding in 2 cases ( $2 \%)$, contralateral pneumothorax in 1 case $(1 \%)$ and severe arrhythmia in 1 patient $(1 \%)$. 
Table 1 Preoperative patient's data

\begin{tabular}{|c|c|c|}
\hline Variables & $\mathrm{N}$ or [IQR] & $\%$ \\
\hline Patient number & 108 & 100 \\
\hline Age, years (median) & 67 [60-73] & - \\
\hline \multicolumn{3}{|l|}{ Gender } \\
\hline Male & 86 & 80 \\
\hline Female & 22 & 20 \\
\hline \multicolumn{3}{|l|}{ Medical comorbidities* } \\
\hline COPD & 10 & 9 \\
\hline Diabetes & 10 & 9 \\
\hline Cardiovascular diseases & 38 & 35 \\
\hline Others & 44 & 41 \\
\hline \multicolumn{3}{|l|}{ Smoking history } \\
\hline Active & 37 & 34 \\
\hline Ex & 44 & 41 \\
\hline \multicolumn{3}{|l|}{ Side of cancer } \\
\hline Left & 64 & 59 \\
\hline Right & 44 & 41 \\
\hline Hospital stay (median) & $14[11-17]$ & \\
\hline \multicolumn{3}{|l|}{ ICU stay } \\
\hline Yes & 59 & 55 \\
\hline No & 49 & 45 \\
\hline ICU stay (median) & $1(0-2)$ & \\
\hline
\end{tabular}

*, one patient can have more than one comorbidity. COPD, chronic obstructive pulmonary disease; ICU, intensive care unit; $I Q R$, interquartile range.

Perioperative complications were noted in 52 cases (48\%): recurrent laryngeal nerve palsy $(n=13,12 \%)$, atrial fibrillation $(\mathrm{n}=12,11 \%)$, respiratory complication $(\mathrm{n}=10$, $9 \%)$, anemia $(n=7,6 \%)$, hemothorax $(n=5,5 \%)$, vascular thrombosis $(n=2,2 \%)$, acute renal failure $(n=1,1 \%)$ and chylothorax $(\mathrm{n}=1,1 \%)$. Long-term complications were observed in 25 cases ( $23 \%$ ), but these data were not available for 5 patients. The most frequent postoperative complication was respiratory failure $(n=7,6 \%)$, followed by cardiac arrhythmia in 4 patients (4\%) and bronchopleural fistula in 2 cases (2\%). There were no cases of intraoperative mortality, while 2 patients died after 2 and 17 days for respiratory failure with a 30 -day mortality rate of $2 \%$. The first patient had a Pancoast tumor and underwent a right
Table 2 Operative and pathological results

\begin{tabular}{|c|c|c|}
\hline Variables & $\mathrm{N}$ & $\%$ \\
\hline \multicolumn{3}{|l|}{ Neoadjuvant therapy } \\
\hline None & 64 & 59 \\
\hline CT & 26 & 24 \\
\hline RT & 2 & 2 \\
\hline $\mathrm{CT}+\mathrm{RT}$ & 16 & 15 \\
\hline \multicolumn{3}{|l|}{ Structural involvement } \\
\hline Aorta & 21 & 20 \\
\hline Left atrium & 24 & 22 \\
\hline Superior vena cava & 23 & 21 \\
\hline Subclavian artery & 8 & 7 \\
\hline Main pulmonary artery & 32 & 30 \\
\hline Intrapericardial cardiovascular invasion & 42 & 39 \\
\hline \multicolumn{3}{|l|}{ Surgical approach } \\
\hline Thoracotomy & 100 & 92 \\
\hline Sternotomy & 1 & 1 \\
\hline Sternothoracotomy & 5 & 5 \\
\hline Clamshell incision & 2 & 2 \\
\hline \multicolumn{3}{|l|}{ Pulmonary resection } \\
\hline Lobectomy & 31 & 29 \\
\hline Bilobectomy & 6 & 5 \\
\hline Pneumonectomy & 56 & 52 \\
\hline Sleeve lobectomy & 12 & 11 \\
\hline Sublobar resection & 3 & 3 \\
\hline \multicolumn{3}{|l|}{ Combined resection } \\
\hline Vascular reconstruction & 31 & 29 \\
\hline Angioplasty or sub-adventitial dissection & 63 & 58 \\
\hline LA resection & 27 & 25 \\
\hline CPB/ECMO & 5 & 5 \\
\hline \multicolumn{3}{|l|}{ Completeness of resection } \\
\hline Ro & 88 & 82 \\
\hline $\mathrm{R}+$ & 20 & 18 \\
\hline \multicolumn{3}{|l|}{ Histologic type } \\
\hline Squamous cell carcinoma & 77 & 71 \\
\hline Adenocarcinoma & 26 & 24 \\
\hline Large cell carcinoma & 1 & 1 \\
\hline
\end{tabular}

Table 2 (continued) 
Table 2 (continued)

\begin{tabular}{|c|c|c|}
\hline Variables & $\mathrm{N}$ & $\%$ \\
\hline Neuroendocrine carcinoma & 1 & 1 \\
\hline Sarcomatoid carcinoma & 2 & 2 \\
\hline Adeno-squamous carcinoma & 1 & 1 \\
\hline \multicolumn{3}{|l|}{$\mathrm{pN}$ or pyN } \\
\hline $\mathrm{N}=0$ & 41 & 38 \\
\hline $\mathrm{N}=1$ & 40 & 37 \\
\hline $\mathrm{N}=2$ & 26 & 24 \\
\hline $\mathrm{N}=3$ & 1 & 1 \\
\hline \multicolumn{3}{|l|}{ pStage or pyStage } \\
\hline IIIA & 77 & 71 \\
\hline IIIB & 29 & 27 \\
\hline IIIC & 1 & 1 \\
\hline \multicolumn{3}{|l|}{ Adjuvant therapy } \\
\hline None & 38 & 35 \\
\hline $\mathrm{CT}$ & 11 & 10 \\
\hline RT & 31 & 29 \\
\hline $\mathrm{CT}+\mathrm{RT}$ & 23 & 21 \\
\hline NA & 5 & 5 \\
\hline
\end{tabular}

CT, chemotherapy; RT, radiotherapy; NA, not available data; CPB, cardiopulmonary bypass; ECMO, extracorporeal membrane oxygenation.

upper lobectomy together with a chest wall resection, subclavian vein and artery resection and reconstruction with vascular grafts. The second patient had a locally advanced adenocarcinoma of the right lung with invasion of the SVC and underwent a right pneumonectomy with vena cava resection and reconstruction. Complications are described in Table 3.

\section{Overall survival (OS)}

After a median follow up of 17 months (IQR, 9-48 months), 28 patients $(28 \%)$ were still alive, $50(50 \%)$ died due to disease relapse and $22(22 \%)$ due to non-cancer-related events. Factors affecting survival at the univariate and multivariate analysis are showed in Table 4. On multivariate analysis, age, squamous histology, no induction therapy and disease recurrence resulted as risk factors for poor longterm out-come. Median OS was 67 months (IQR, 22-
Table 3 Details of the peri and postoperative complications

\begin{tabular}{lcc}
\hline Variables & $\mathrm{N}$ & $\%$ \\
\hline Intraoperative complications (total) & 4 & 4 \\
Bleeding & 2 & 2 \\
Contralateral pneumothorax & 1 & 1 \\
Severe arrhythmia & 1 & 1 \\
Perioperative complications (total) & $52^{*}$ & 48 \\
Recurrent laryngeal nerve palsy & 13 & 12 \\
AF & 12 & 11 \\
Respiratory complication & 10 & 9 \\
Anemia & 7 & 6 \\
Hemothorax & 5 & 5 \\
Vascular thrombosis & 2 & 2 \\
Acute renal failure & 1 & 1 \\
Chylothorax & 12 & 1 \\
Others & 11 & 10 \\
Long-term complications (total) & 25 & 23 \\
Cardiac arrhythmia & 4 & 4 \\
Respiratory failure & 7 & 6 \\
Bronchopleural fistula & 2 & 2 \\
Others & 11 \\
\hline One patient can have more than & 12 \\
\hline
\end{tabular}

*, one patient can have more than one complication. $\mathrm{AF}$, atrial fibrillation.

115 months). One-, 3- and 5-year survival rates were $75 \%$, $34 \%$ and $27 \%$, respectively (Figure 2). Long-term survival was not significantly different between groups of vascular invasion as showed in Figure $3 \mathrm{~A}$.

\section{Recurrence and disease-free survival (DFS)}

Sixty-six patients $(61 \%)$ experienced recurrence and the patterns of relapse were: local in 21 cases (19\%), distant in 33 patients (30\%) and local + distant in 13 cases (12\%). Nine patients experienced more than one recurrence. Data about relapse were not available for 6 patients. Relapse was treated with radiotherapy in 11 cases (10\%), with chemotherapy in 17 patients (16\%), with surgery in 5 cases $(5 \%)$ and with a combination of treatments in 7 patients $(6 \%)$. Median DFS was 7.5 months (IQR, 3.75-14.5 months). These data are summarized in Table 5. The age, squamous histology and R1-resection were risk factors for disease 
Table 4 Univariate and multivariate analysis for survival

\begin{tabular}{|c|c|c|c|c|}
\hline Clinical factors & Univariate analysis ( $P$ value) & \multicolumn{3}{|c|}{ Multivariate analysis } \\
\hline Age & 0.01 & 0.004 & 4.4 & $1.1-23.8$ \\
\hline Gender (female/male) & 0.05 & ns & - & - \\
\hline Comorbidity & 0.03 & ns & - & - \\
\hline Type of vascular invasion & 0.4 & - & - & - \\
\hline Induction therapy (no/yes) & 0.02 & 0.01 & 7.1 & $3.3-63.2$ \\
\hline Type of lung resection & 0.1 & - & - & - \\
\hline Post-operative morbidity & 0.7 & - & - & - \\
\hline Adjuvant therapy (no/yes) & 0.3 & - & - & - \\
\hline Disease recurrence & 0.0001 & 0.002 & 11.7 & $3.9-76.4$ \\
\hline
\end{tabular}

$\mathrm{HR}$, hazard ratio; $\mathrm{Cl}$, confidence interval; ns, not significant.

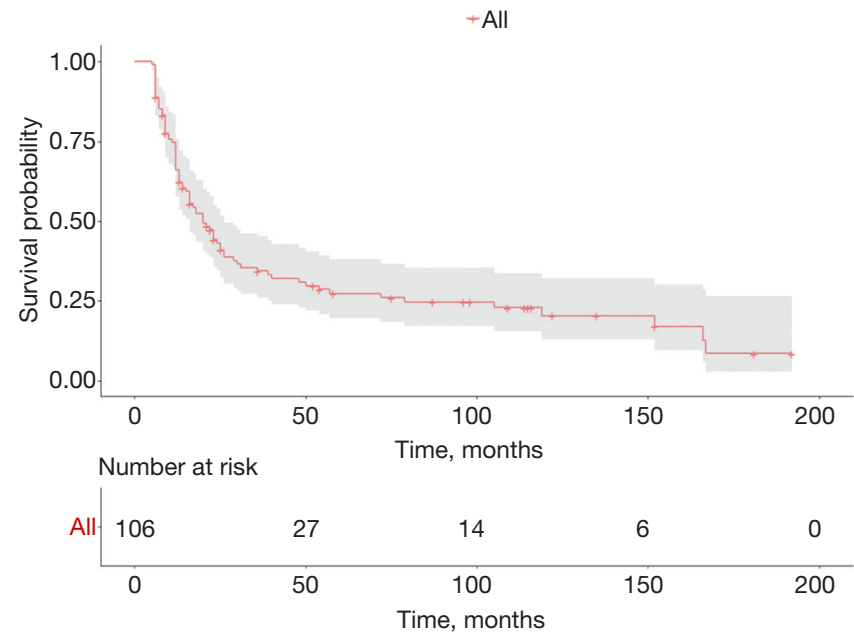

Figure 2 Overall survival (Kaplan-Meier curve).

recurrence at the multivariate analysis (Table 6).

\section{Discussion}

The survival benefits of surgical resection for T4-NSCLC invading the aorta, main $\mathrm{PA}$, the $\mathrm{LA}, \mathrm{SVC}$ and major mediastinal vessels is still under debate (1-7). To most of the patient's surgery is denied because of significant risk of intraoperative and post-operative morbidity and mortality, in particular when severe pre-existing comorbidities are present. Nonetheless, a continuous evolution observed in operative management, surgical technologies and neoadjuvant protocols have improved the prognosis of these very complex patients $(7,8)$. Different studies attempted to identify the patients who could benefit from complex surgical procedure within a heterogeneous population of T4-NSCLC $(9,10)$. In our study we decided to collect only patients with T4-NSCLC due to major vessels or heart infiltration. In the most recent series, despite a careful selection of the patients, the perioperative mortality range between $0.1 \%$ to $14 \%$ and morbidity between $31 \%$ to $54 \%(1-11)$. In our study, we report a $2 \%$ mortality related to respiratory failure/ARDS that is considered, in most of the previous studies, as the main postoperative complication, in particular after pneumonectomy (9-11). Morbidity rate, as reported in literature, is quite high, and it is mainly related to respiratory infection/atelectasis (9\%), supraventricular arrhythmia (11\%) and laryngeal nerve palsy (12\%). Pneumonectomy is the most performed lung resection as reported by other similar series (1-11), that obviously justifies the high-rate of perioperative morbidity. In literature another dreaded complication, with an incidence about $2 \%$ to $5 \%$, is the bronchopleural fistula; in our series we report this complication, that was treated with thoracostomy, in 2 patients $(2 \%)$, who 
A
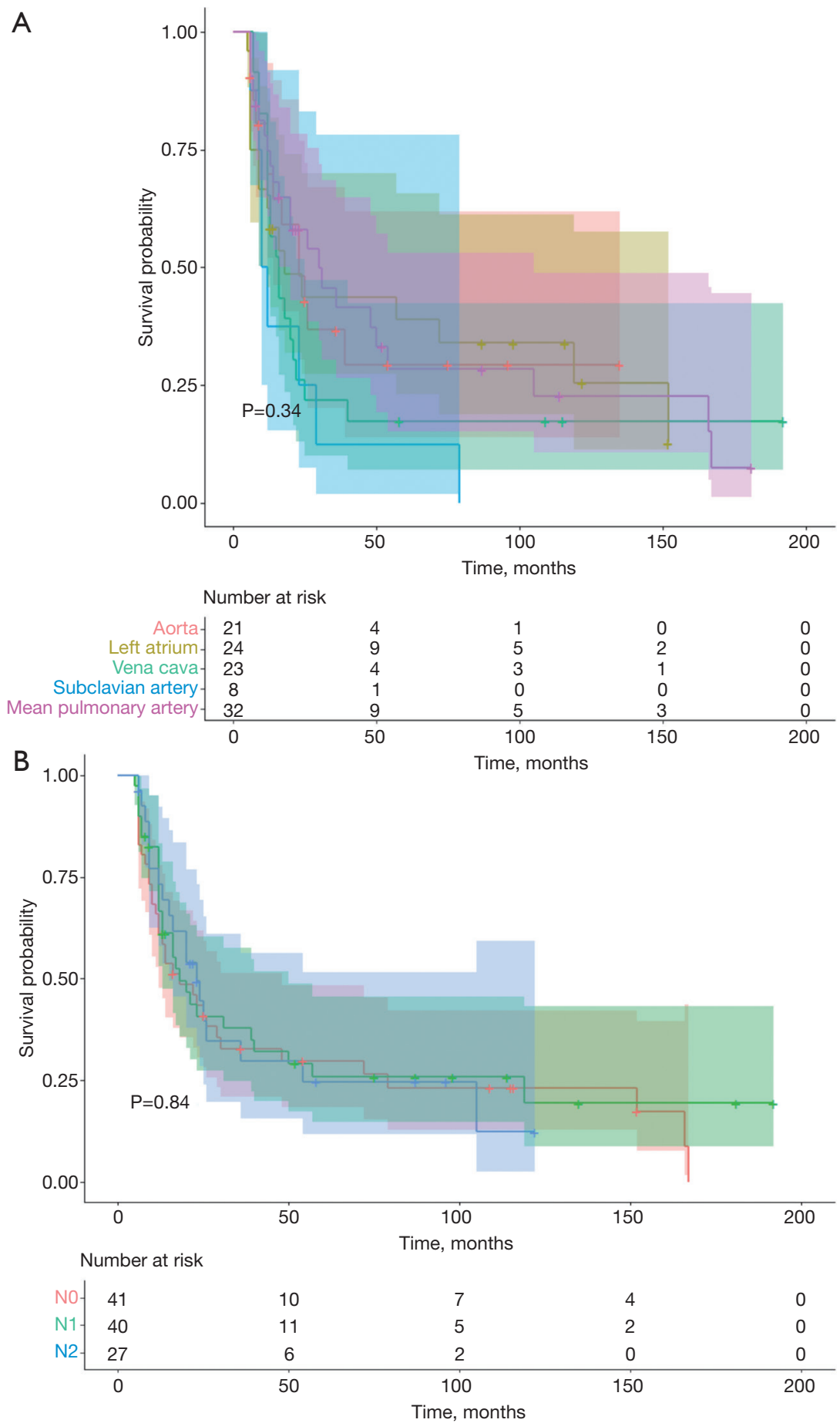

Figure 3 Kaplan-Meier curves stratified by type of vascular infiltration (A) and by nodal involvement (B).

underwent a right pneumonectomy (11). In this study there is no statistical difference between perioperative morbidity and mortality with respect to the type of vascular invasion. We report a R0 resection rate of $82 \%$. Despite this data lack in many series, the reported rate of R1-2 resection in literature range between $6 \%$ to $14 \%$ for $\mathrm{T} 4$ NSLC and it is even higher in case of other thoracic malignancies invading the heart and the great vessels (12). 
In very selected cases, extracorporeal circulatory support could be used to achieve an oncological radical resection, in particular for extended left atrium or aorta resection. In literature, the need for circulatory support does not exceed $5 \%$ of the cases with T4-NSCLC (13). In our experience, we used an extracorporeal support device in 5 cases (4.6\%): a left heart by-pass was used in four aortic

Table 5 Pattern and treatment of recurrence

\begin{tabular}{lll}
\hline Variables & $\mathrm{N}$ & $\%$ \\
\hline Recurrence & 66 & 61 \\
Yes & 36 & 33 \\
No & 21 & 19 \\
Local & 33 & 30 \\
Distant & 13 & 12 \\
Local + distant & & \\
Treatment of relapse & 16 & 15 \\
None & 11 & 10 \\
RT & 17 & 16 \\
CT & 5 & 5 \\
Surgery & 7 & 6 \\
\hline Combination of RT, CT and surgery & & \\
\hline
\end{tabular}

$\mathrm{CT}$, chemotherapy; RT, radiotherapy. resection and reconstruction with vascular graft and full cardiopulmonary by-pass in one case of main PA resection and reconstruction. The post-operative period of these patients was uneventful.

Long-term survival range between $30 \%$ and $40 \%$ in many series (1-10). Yildizeli et al. reported an overall 5-year survival of $38.4 \%$ for T4-NSCLC over a period of 25 years (9). Martini et al. (14), as well, report for R0 resected for NSCLC invading the mediastinum a 5-year survival of $30 \%$ that reaches $19 \%$ when analysing R0 and R1 resected cases. Well known factors affecting survival are the completeness of the resection, the tumour stage, the $\mathrm{N}$ factor downstaging after neoadjuvant therapy and the invasion of the subclavian artery $(1-12,14,15)$. Moreover, in our experience, Pancoast tumour with subclavian artery infiltration had a poorer long-term survival compared to other groups even without reaching the statistical significance. At our multivariate analysis the age $(\mathrm{P}=0.004)$, histology $(0.02)$, diseaserecurrence $(0.002)$ and induction therapy $(0.01)$ were able to influence long-term survival. In particular, the feasibility of induction/neoadjuvant therapy before surgery for $\mathrm{T} 4$ NSCLC has been demonstrated effective in improving survival also in case of great vessels infiltration $(8,14,15)$. The three general goals of neoadjuvant therapy is tumour downsizing, eradication of micrometastases and clearance of the involved local lymph nodes. Clinical N2 disease is considered an absolute contraindication to surgery by many authors $(8,14-16)$. In our experience, a single station $\mathrm{cN} 2$

Table 6 Univariate and multivariate analysis for disease recurrence

\begin{tabular}{|c|c|c|c|c|}
\hline Clinical factors & Univariate analysis ( $\mathrm{P}$ value) & \multicolumn{3}{|c|}{ Multivariate analysis } \\
\hline Age & 0.03 & 0.05 & 3 & $1.7-4.6$ \\
\hline Gender (female/male) & 0.05 & ns & - & - \\
\hline Comorbidity & 0.2 & - & - & - \\
\hline Type of vascular invasion & 0.09 & - & - & - \\
\hline Induction therapy & 0.04 & ns & - & - \\
\hline Type of lung resection & 0.7 & - & - & - \\
\hline Post-operative morbidity & 0.2 & - & - & - \\
\hline Adjuvant therapy & 0.3 & - & - & - \\
\hline
\end{tabular}

$\mathrm{HR}$, hazard ratio; $\mathrm{Cl}$, confidence interval; ns, not significant. 
disease or a clear down staging of the involved nodes after neoadjuvant chemotherapy are not a contraindication to surgery. In our analysis, the $\mathrm{N}$ factor doesn't influence the long-term survival or the DFS (Figure 3B). Furthermore, in our experience, there is no difference in survival between aorta, LA, SVC and main PA infiltration.

Spaggiari et al. (10) reported a 5-year survival of $37 \%$ in 14 patients that underwent aorta resection without cardiopulmonary by-pass. Klepetko et al. (8) reported a 4-year survival of $25 \%$ in 7 patients that underwent en bloc resection of left lung and aorta with a full cardiopulmonary by-pass in the $86 \%$ of the cases. In a multicenters study, Marulli et al. (15) report a median overall survival of 31 months; only gender and descending thoracic aortic infiltration were identified as significant independent factors associated with better survival. Moreover, in the same study, the $\mathrm{N}$-status didn't influence recurrence rate and site of recurrence. We used a left heart by-pass in four patients requiring an-bloc aorta resection with vascular by-pass, whereas in the remaining 16 patients the extracorporeal life support was not necessary and the aorta was reconstructed with a patch or protected by previous endoprosthesis placement. We report a satisfactory 5-year survival of $31 \%$ similar to the other reported experience $(8,11,14,15)$.

PA reconstruction with end-to-end anastomosis, patch, or interposition graft was performed along with sleeve lung resection (32\%) or lobectomy/bilobectomy (41\%). Mu et al. reported a 5 -year survival of $53 \%$ for PA reconstruction (16), instead, Wang et al. (17) report a 5-year survival of $46 \%$. Our results show a 5-year survival of $28 \%$ that reflect a more compromised category of patients, in which main PA resection and pneumonectomy was the most frequently associated lung resection, in one case performed with the aid of cardiopulmonary by-pass, compared with the literature series.

NSCLC invading the LA comprises a dis-homogeneous category of patients in whom the tumour might infiltrated the base of the pulmonary veins, the true left atrial wall or just be a neoplastic embolus that floats at the origin of the pulmonary vein. Dartevelle et al. (1) reported a 5-year survival of $22 \%$; moreover, all patients with embolic left atrial disease died of hematogenous metastasis with just 6 months of disease-free interval. Similarly, Spaggiari reports a 5 -year survival of $27 \%$ for atrial resection combined with pneumonectomy (18). Better results were published by Galvaing et al. (19), who advocate a positive effect of the extensive use of neoadjuvant therapy and the surgical dissection of the Sondergaard groove to have extra tissue for larger surgical resection margins. In their experience the 5 -year survival was $44 \%$ (19), not substantially different from our results (5-year survival $39 \%)$. Indeed, we routinely use induction therapy for these patients and, when necessary, a careful dissection of the interatrial groove was performed to increase surgical margins, by using this approach we have never had necessity of circulatory support for these kinds of procedures.

In literature, 5-year survival of patients who underwent a vena cava resection for NSCLC range between 15\% to 29\% and it is significantly influenced by $\mathrm{N} 2$ disease, $\mathrm{R}$ status and necessity of total caval resection by using a prosthetic bypass $(11,20,21)$. Shargall et al. (11) report a 3-year survival of $57 \%$ in their 15 -year experience of T4 invading the vena cava. Survival of N2 patients was not significantly worse than those with $\mathrm{N} 0 / \mathrm{N} 1$, as reported in our study. Induction therapy seems to reduce recurrence rate disease but without influence on survival. In our experience the use of induction therapy seems to improve survival even in case of SVC infiltration; indeed, we report a 3 -and 5 -year survival of $22 \%$ and $17 \%$ respectively.

Sixty-six patients $(61 \%)$ in our study had disease recurrence, at the multivariate analysis factors that influence the risk of recurrence were histology (0.01), age (0.05) and R1 resection (0.003). Median DFS was 7.5 months. In literature, recurrence rate range between $50 \%$ to $66 \%$ and in particular in patients who had R1 resection, N2/3 disease and who didn't receive induction therapy $(6-8,11)$. In our experience, induction therapy influence positively not only overall survival but also DFS. We didn't find any difference between groups of vascular resection and $\mathrm{N}$ positive versus N0 disease. Obviously, this aspect is not clear and further studies with a larger series of patients are required.

\section{Conclusions}

In conclusion, regarding our experience, surgical treatment of T4 NSCLC with vessels or heart invasion demonstrates an acceptable risk in terms of mortality and morbidity. The indications for such demolitive surgery should be clearly weighed with respect to mortality and morbidity risks, in particular for older patients with multiple comorbidities. A multidisciplinary evaluation and approach are mandatory to improve survival and to reduce recurrence of the disease; in particular, induction chemotherapy seems to have a positive effect. Current data and literature review suggest that for NSCLC invading the aorta, main PA, LA, SVC and subclavian artery an extended pulmonary resection may be 
warranted to selected patients treated in high volume and experienced centers.

\section{Acknowledgments}

Funding: None.

\section{Footnote}

Provenance and Peer Review: This article was commissioned by the Guest Editors (Davide Tosi and Alessandro Palleschi) for the series "The treatment of locally advanced lung cancer" published in Current Challenges in Thoracic Surgery. The article has undergone external peer review.

Data Sharing Statement: Available at https://ccts.amegroups. com/article/view/10.21037/ccts-20-63/dss

Conflicts of Interest: All authors have completed the ICMJE uniform disclosure form (available at https://ccts. amegroups.com/article/view/10.21037/ccts-20-63/coif). The series "The treatment of locally advanced lung cancer" was commissioned by the editorial office without any funding or sponsorship. The authors have no other conflicts of interest to declare.

Ethical Statement: The authors are accountable for all aspects of this work in ensuring that questions related to the accuracy or integrity of any part of this work are appropriately investigated and resolved. Study approval by local ethic commitment was achieved (No. CH-T00.4598PD19). Informed consent was taken from all individual participants. The study was conducted in accordance with the Declaration of Helsinki (as revised in 2013).

Open Access Statement: This is an Open Access article distributed in accordance with the Creative Commons Attribution-NonCommercial-NoDerivs 4.0 International License (CC BY-NC-ND 4.0), which permits the noncommercial replication and distribution of the article with the strict proviso that no changes or edits are made and the original work is properly cited (including links to both the formal publication through the relevant DOI and the license). See: https://creativecommons.org/licenses/by-nc-nd/4.0/.

\section{References}

1. Dartevelle PG, Mitilian D, Fadel E. Extended surgery for T4 lung cancer: a 30 years' experience. Gen Thorac Cardiovasc Surg 2017;65:321-8.

2. Stella F, Dell'Amore A, Caroli G, et al. Surgical results and long-term follow-up of T4-non-small cell lung cancer invading the left atrium or the intrapericardial base of the pulmonary veins. Interact Cardiovasc Thorac Surg 2012;14:415-9.

3. Park B, Cho JH, Kim HK, et al. Long-term survival in locally advanced non-small cell lung cancer invading the great vessels and heart. Thorac Cancer 2018;9:598-605.

4. Tanaka Y, Hokka D, Ogawa H, et al. Surgery for Malignant Lesions of the Chest Which Extensively Involved the Mediastinum, Lung, and Heart. Gen Thorac Cardiovasc Surg 2017;65:365-73.

5. LoCicero J III, Feins RH, Colson YL, et al. Shields' general thoracic surgery. Philadelphia, 2019.

6. Ilonen I, Jones DR. Initial extended resection or neoadjuvant therapy for $\mathrm{T} 4$ non-small cell lung cancerWhat is the evidence? Shanghai Chest 2018;2:76.

7. Reardon ES, Schrump DS. Extended resection of nonsmall cell lung cancer lung cancer invading the aorta, pulmonary artery, left atrium, or esophagus: can be justified? Thorac Surg Clin 2014;24:457-64.

8. Klepetko W, Wisser W, Birsan T, et al. T4 lung tumors with infiltration of the thoracic aorta: is an operation reasonable? Ann Thorac Surg 1999;67:340-4.

9. Yildizeli B, Dartevelle PG, Fadel E, et al. Results of primary surgery with T4 non-small cell lung cancer during a 25 -year period in a single center: The benefit is worth the risk. Ann Thorac Surg 2008;86:1065-75.

10. Spaggiari L, Tessitore A, Casiraghi M, et al. Survival after extended resection for mediastinal advanced lung cancer: lesson learned on 167 consecutive cases. Ann Thorac Surg 2013;95:117-25.

11. Shargall $Y$, de Perrot $M$, Keshavjee S, et al. 15 years single center experience with surgical resection of the superior vena cava for non-small cell lung cancer. Lung Cancer 2004;45:357-63.

12. Park BJ, Bacchetta M, Bains MS, et al. Surgical management of thoracic malignancies invading the heart or great vessels. Ann Thorac Surg 2004;78:1024-30.

13. Filippou D, Kleontas A, Tentzeris V, et al. Extended resections for the treatment of patients with $\mathrm{T} 4$ stage IIIA non-small cell lung cancer (NSCLC) (T4N0-1M0) with or without cardiopulmonary bypass: a 15 -year two-center experience. J Thorac Dis 2019;11:5489-501.

14. Martini N, Yellin A, Ginsberg RJ, et al. Management of non-small cell lung cancer with direct mediastinal 
involvement. Ann Thorac Surg 1994;58:1447-51.

15. Marulli G, Rendina A, Klepetko W, et al. Surgery for T4 lung cancer invading the thoracic aorta: do we push the limits? J Surg Oncol 2017;116:1141-9.

16. Mu JW, Wang YG, Li J, et al. Surgical results of T4 lung cancer invading left atrium and great vessels. Zhonghua Yi Xue Za Zhi 2008;88:383-6.

17. Wang XX, Liu TL, Yin XR. Surgical treatment of IIIb-T4 lung cancer invading left atrium and great vessels. Chin Med J (Engl) 2010;123:265-8.

18. Spaggiari L, D'Aiuto M, Veronesi G, et al. Extended pneumonectomy with partial resection of left atrium,

doi: $10.21037 /$ ccts-20-63

Cite this article as: De Franceschi E, Dell'Amore A, Bellini A, Pangoni A, Russo MD, Rocchi M, Comacchio GM, Cannone G, Mammana M, Schiavon M, Zuin A, Rea F. T4 non-small cell lung cancer invading the heart or the major thoracic vessels. Curr Chall Thorac Surg 2020;2:27. without cardiopulmonary bypass, for lung cancer. Ann Thorac Surg 2005;79:234-40.

19. Galvaing G, Tardy MM, Cassagnes L, et al. Left atrial resection for T4 lung cancer without cardiopulmonary bypass: technical aspects and outcomes. Ann Thorac Surg 2014;97:1708-13.

20. Spaggiari L, Magdeleinat P, Kondo H, et al. Results of superior vena cava resection for lung cancer. Analysis of prognostic factors. Lung Cancer 2004;44:339-46.

21. Dartevelle P, Macchiarini P, Chapelier A. Technique of superior vena cava resection and reconstruction. Chest Surg Clin N Am 1995;5:345-58. 